\title{
Die verkehrsbedingte Entwicklung der Stadt Olten
}

Urs Wiesli

$\mathrm{Zu}$ hohe Dichte im froburgischen Städtesystem, entsprechend kleinflächiges Marktgebiet und später das politisch-wirtschaftliche Abhängigkeitsverhältnis von Solothurn werden dafür verantwortlich gemacht, daß sich Olten trotz hervorragender Verkehrslage bis 1850 nur unwesentlich über den bescheidenen römisch-mittelalterlichen Mauerring hinaus entwickelt und damals nur 1640 Einwohner und somit weniger als einige der umliegenden Dörfer gezählt hat.

Erst die neue Funktion als Eisenbahnknotenpunkt hat der Stadt seit 1856 neue Impulse verliehen. Die Folgen waren schnelles Anwachsen der Bevölkerungszahl, der Zuzug von rund 70 Industrieunternehmen vor allem längs der Bahnlinien, die Verlagerung des Straßendurchgangsverkehrs in die Bahnhofzone und die Abwanderung der meisten zentralen Dienste aus der Altstadt an die neuen Zufahrtsstraßen zum Bahnhof, an denen die City-Bildung rasche Fortschritte macht. Etwa die Hälfte der berufstätigen Bevölkerung arbeitet heute im Dienstleistungsbereich, und zwar vorwiegend in Verkehrsund Handelsbetrieben. Die gute Verkehrslage bewirkte, daß 1960 die Zupendler 70\% der wohnhaften Berufstätigen ausmachten. Indessen ist das wirtschaftliche Umland Oltens infolge der allzu nahen Kantonsgrenzen, des Juras und der Konkurrenz der Zentren Aarau und Zofingen räumlich eingeschränkt.

Die gesamte Entwicklung ist größtenteils bahnbedingt, doch erweist sich heute gerade der überdurchschnittlich hohe Raumbedarf der SBB als Hemmnis der weitern Entwicklung. Größere Industrieareale fehlen, die bestehenden sind zwischen Bahnanlagen eingeklemmt und nicht mehr ausdehnbar. Vierzehn Industrien sind in den letzten zehn Jahren abgewandert, vorwiegend in die Gegend des Nationalstraßenknotens im Gäu, von wo die Region Olten ohne Zweifel neue verkehrsbedingte Impulse erfahren wird. Auch das Wohnareal ist knapp geworden. Die Bevölkerungszahl nahm 1967/68 sogar leicht ab. Während bis zum Zweiten Weltkrieg Oltens Wohnquartiere fast ausschließlich aus gartenumgebenen Einfamilienhäusern bestanden und mehrere Straßen mehrheitlich von Bahnangestellten bewohnt wurden, drängt sich heute immer mehr die Wohnblock- und Hochhausbauweise auf. Mehrere Straßenzüge mit erst 70jährigen Häusern sind gegenwärtig in völliger baulicher Wandlung begriffen. Geplant ist auch eine neue Wohnsiedlung am südwestlichen Stadtrand für gegen 10000 Einwohner.

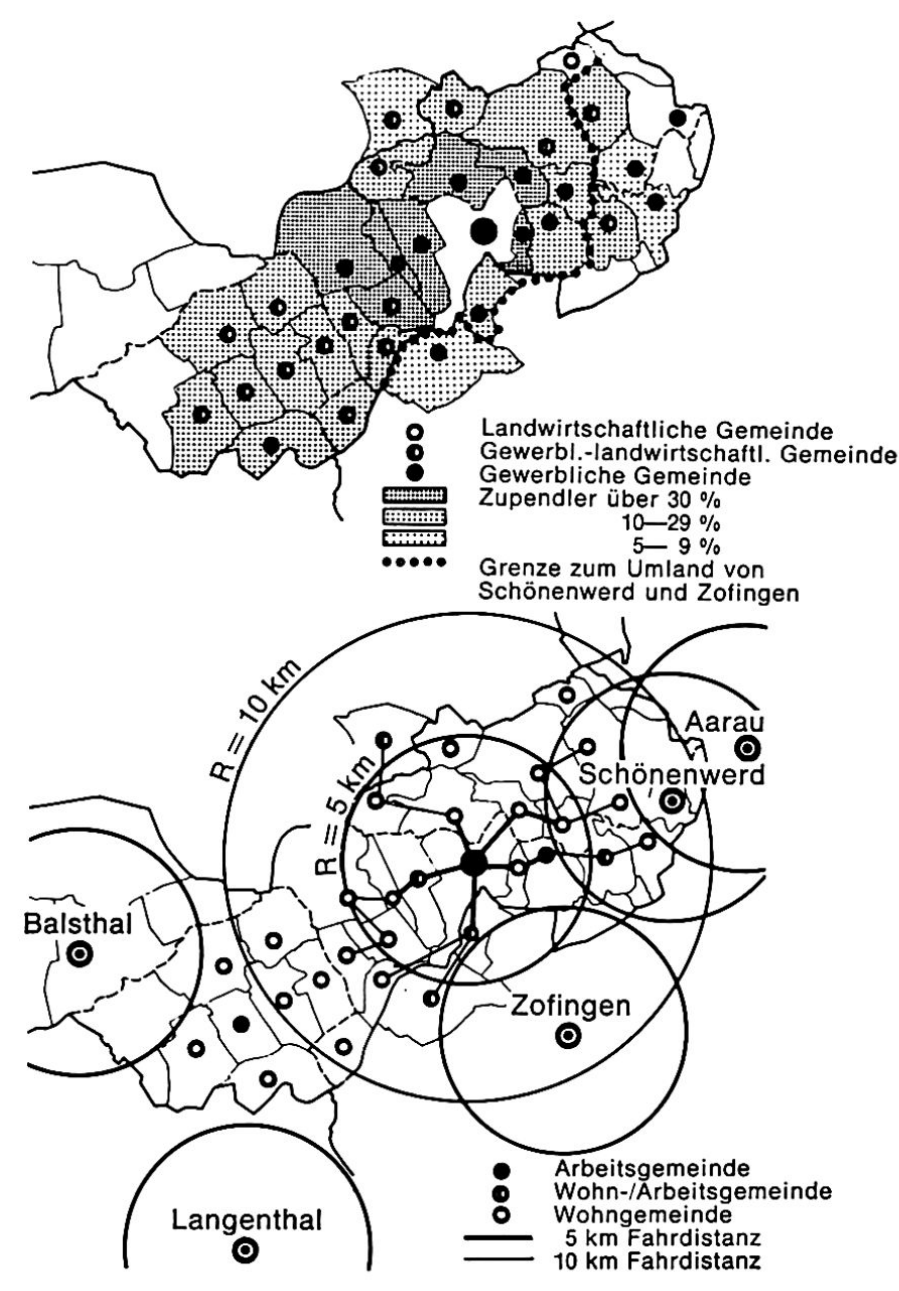

Bereits wachsen einige Umlandgemeinden rascher als das zentralörtliche Olten.

"Olten vor dem Bahnbau» wurde anläßhich der Exkursion mit Diapositiven vorgeführt. Hierauf folgte eine Orientierung über die heutige Stadt von der Dachterrasse des neuen Stadthauses aus. Eine Carfahrt durch die Bahn- und Industrieareale und durch einige Außenquartiere demonstrierte Platzmangel, Schwerpunktverlagerung und verkehrsbedingte bauliche Entwicklung. Vom Säli-Schlößli aus bot sich Gelegenheit, auf die Verkehrslage im Zusammenhang mit den naturräumlichen Faktoren einzugehen. Am Nachmittag schloß sich eine Fahrt durch die von Oltens Arealmangel profitierenden Umlandgemeinden und zum Autobahnknoten im Gäu mit der dort im Entstehen begriffenen Industriekonzentration und dem entsprechenden Landschaftswandel an. 